\title{
Mathematical Modeling of Polyphosphazenes
}

\author{
aDepartment of Chemistry, University of Sahiwal, Sahiwal 57000, Pakistan. \\ bDepartment of Computer Science, University of Sahiwal, Sahiwal 57000, Pakistan. \\ 'Department of Chemistry, Govt. Post Graduate College Sahiwal 57000, Pakistan \\ *Corresponding Author E-mail: mabiduet@gmail.com; akq999@yahoo.com
}

Amin Abid ${ }^{a}$, Shafiq Hussain ${ }^{b}$, Ahmad Kaleem Qureshi*a, Muhammad Jamilc, Hajira Rehman ${ }^{a}$, Abdur Rauf

\section{DOI: 10.2478/acmy-2021-0001}

\section{Abstract:}

Polyphosphazenes was synthesized and their self assembly behavior was observed as reported in our previous work [1-5]. A number of experiments were carried out to study the polymerization behavior at various conditions of the polymerization time and temperature. The experimental data were analyzed by graphical and statistical methods and it was found that the polymerization phenomena was controlled by the synthesis time, i.e. $M_{w}=M_{o} e^{k_{t} t_{s}}$, where $M_{w}$ is molecular weight of the polymer at time $t_{s,} M_{0}(=203.24)$ is pre-exponential factor in the model and $\boldsymbol{k}_{s}(=\mathbf{1 . 0 6 8 6 )}$ is synthesis rate constant for the polymer.

Keywords: Mathematical Modeling, Polyphosphazenes, Computational Chemistry

\subsection{Introduction}

Polyphosphazenes have gained lots of attention in biological applications due to their unique properties [1-7]. The backbone of this polymer contains alternating Nitrogen and Phosphorous atoms which have two pendant groups on each phosphorous atom. The selection of side groups is very important to tailor the polymer for desirable properties. The presence of hydrophilic side groups like chlorine, amino, amino acid ester, glycolate derivatives etc. make the polymer chain susceptible to hydrolysis [8-11] and useful for biomedical applications such as tissue engineering, drug delivery, short term implants etc. [1-3]. The degradation mechanism of polyphosphazene has not been fully understood but the current scheme is result of various experimental studies [4,5]. During the hydrolysis, water molecules attack on side groups replacing it with the hydroxyl group. Hydroxyl group poses electron withdrawing effect on the chain and resultantly chain tautomerizes facilitating the degradation finally splitting into the end products such as ammonia, phosphate, phosphoric acid and conjugate acid of side group [1-5].

Mathematical models can be useful tool for interpretation of hydrolytic degradation of polymers. Traditional experimental methods may not be good source of knowledge of the reaction thermodynamics which is provided by these mathematical models [12]. Density functional theory (DFT) [13] method and classical molecular dynamics (MD) [14] has been useful tool for investigation of molecular geometries, electronic structure and transition state geometries for substitutions of polyphosphazenes. Adam A. Skelton et al studied the hydrolysis mechanism of dichlorophosphazene trimer by density functional theory (DFT) method [15], atom centered density matrix propagation (ADMP) and Ab initio molecular dynamics (AIMD) [16,17] calculations [18-20].

Many researchers synthesized polymeric materials and they used for applications for mathematical modeling [21-30].

In this study, we have investigated mathematical modeling for the synthesis using $\mathrm{AlCl}_{3}$ as catalyst, reaction rate, molecular weight, polydispersity index (PDI) of polyphosphazene. For this study, we have used exponential method for mathematical modeling.

\subsection{Results and Discussion}

Synthesis of PDCP from HCCP in the presence of catalyst is shown in (Fig. 1):<smiles>CC(C)N=P(Cl)(Cl)C(C)(C)Cl</smiles>

Figure 1: Synthesis of PDCP from HCCP [1-5]

\subsection{Synthesis behavior of the polymer}

\subsubsection{Effect of synthesis time on molecular weight}

To determine the time sensitivity for the synthesis behavior of the polymer, the values of the molecular weight $\left(\mathrm{M}_{\mathrm{w}}\right)$, were analyzed by graphical and statistical methods. The effect of synthesis time on the polymer weight indicates that the weight of the polymer increases up to a certain time and then it falls down as shown in Fig. 2. The results show that from 3 to $4 \mathrm{hrs,} \mathrm{the} \mathrm{increase} \mathrm{in} \mathrm{the} \mathrm{molecular} \mathrm{weight} \mathrm{of} \mathrm{the} \mathrm{polymer} \mathrm{is} \mathrm{not} \mathrm{significant,} \mathrm{therefore} \mathrm{it} \mathrm{has}$ been omitted from the graphical and statistical analysis. Experimental results indicate that the synthesis process of the polymer is a function of the reaction time (from 4 to $10 \mathrm{hrs}$ ), following the semi empirical model:

$$
M_{w}=M_{o} e^{k_{s} t_{s}}
$$

Where, $\boldsymbol{M}_{w}$ is molecular weight of the polymer at synthesis time $t_{s}$ for known amount of the catalyst at $250{ }^{\circ} \mathrm{C}, M_{0}(=203.24)$ is pre-exponential factor in the model and $k_{s}(=1.0686)$ is synthesis rate constant for the polymer. For ascending order, putting the values in eq. (3) we have following eq. 4 :

$M_{w}=203.24 e^{1.068 t_{s}}$

The value of coefficient of determination (0.9571) indicates that the applicability of the suggested model is good [18] and a thermally cross-linked ternary co-polymer synthesized for targeted drug delivery applications and the analysis of swelling data indicated the exponential relation with $\mathrm{pH}$ of the swelling media.

For decreasing order, the synthesis behavior of the polymer was also analyzed by graphical and statistical methods. However, the value of coefficient of determination (0.7898) indicates that the exponential relation is not good. For increasing order, the suggested model may be used to extend the study at a pilot scale work to synthesize the polymer at certain parametric conditions. The design parameters may need some further studies at an industrial scale, however, the suggested semi empirical models may be of value to the researches confronted with the need to synthesize such typical drug delivery polymers. 
Table 1: Synthesis Conditions of PDCP from HCCP

\begin{tabular}{|c|c|c|c|c|c|c|c|c|c|}
\hline \multirow{2}{*}{ Samples } & \multicolumn{2}{|c|}{ Wt. of HCCP } & \multicolumn{3}{|c|}{$\mathrm{AlCl}_{3}$ Catalyst } & \multirow{2}{*}{$\frac{\text { Reaction time }}{\text { hrs }}$} & \multirow[t]{2}{*}{ Mwa } & \multirow[t]{2}{*}{ PDI } & \multirow[t]{2}{*}{ Phase of PDCP } \\
\hline & $\mathrm{g}$ & $\mathrm{mmol}$ & $\mathrm{g}$ & $\mathrm{mmol}$ & $\% \mathrm{wt}$ & & & & \\
\hline 1 & 2.00 & 5.75 & 0.100 & 0.75 & 5 & 3 & $1.83 \times 10^{4}$ & 1.4 & Viscous liquid(non-crosslinked) \\
\hline 2 & 1.66 & 4.77 & 0.083 & 0.62 & 5 & 4 & $1.72 \times 10^{4}$ & 1.1 & Viscous liquid(non-crosslinked) \\
\hline 3 & 3.30 & 9.48 & 0.165 & 1.24 & 5 & 5 & $2.89 \times 10^{4}$ & 1.9 & Viscous liquid(non-crosslinked) \\
\hline 4 & 2.40 & 6.90 & 0.12 & 0.90 & 5 & 6 & $1.63 \times 10^{5}$ & 1.6 & Viscous liquid(non-crosslinked) \\
\hline 5 & 1.90 & 5.46 & 0.096 & 0.72 & 5 & 7 & $3.41 \times 10^{5}$ & 1.2 & Viscous liquid(non-crosslinked) \\
\hline 6 & 3.51 & 10.10 & 0.176 & 1.32 & 5 & 8 & $2.74 \times 10^{4}$ & 2.2 & Viscous liquid(non-crosslinked) \\
\hline 7 & 2.38 & 6.84 & 0.12 & 0.899 & 5 & 9 & $1.56 \times 10^{4}$ & 1.5 & Viscous liquid(non-crosslinked) \\
\hline 8 & 1.50 & 4.31 & 0.075 & 0.56 & 5 & 10 & $1.26 \times 10^{4}$ & 1.4 & Viscous liquid(non-crosslinked) \\
\hline 9 & 0.94 & 2.70 & 0.047 & 0.35 & 5 & 13 & $4.04 \times 10^{5}$ & 1.3 & Viscous liquid(non-crosslinked) \\
\hline 10 & 1.10 & 3.16 & ---- & ---- & 0 & 5 & ---- & ---- & solid phase (crosslinked) \\
\hline 11 & 1.22 & 3.51 & 0.012 & 0.09 & 1 & 5 & ----- & ----- & solid phase (crosslinked) \\
\hline 12 & 0.71 & 2.04 & 0.0142 & 0.106 & 2 & 5 & ---- & ----- & solid phase (crosslinked) \\
\hline 13 & 1.05 & 3.02 & 0.032 & 0.24 & 3 & 5 & $3.66 \times 10^{5}$ & 1.5 & Viscous liquid(non-crosslinked) \\
\hline 14 & 1.69 & 4.86 & 0.07 & 0.524 & 4 & 5 & $1.96 \times 10^{4}$ & 1.6 & Viscous liquid(non-crosslinked) \\
\hline 15 & 0.89 & 2.56 & 0.045 & 0.34 & 5 & 5 & $1.94 \times 10^{4}$ & 1.7 & Viscous liquid(non-crosslinked) \\
\hline 16 & 0.86 & 2.47 & 0.0516 & 0.39 & 6 & 5 & $1.81 \times 10^{4}$ & 1.5 & Viscous liquid(non-crosslinked) \\
\hline 17 & 1.96 & 6.63 & 0.1372 & 1.028 & 7 & 5 & $1.99 \times 10^{4}$ & 1.5 & Viscous liquid(non-crosslinked) \\
\hline 18 & 1.00 & 2.88 & 0.08 & 0.599 & 8 & 5 & $1.57 \times 10^{4}$ & 1.8 & Viscous liquid(non-crosslinked) \\
\hline 19 & 1.00 & 2.88 & 0.09 & 0.67 & 9 & 5 & $1.72 \times 10^{4}$ & 1.7 & Viscous liquid(non-crosslinked) \\
\hline 20 & 3.51 & 10.1 & 0.35 & 2.62 & 10 & 5 & $5.74 \times 10^{3}$ & 1.2 & Viscous liquid(non-crosslinked) \\
\hline
\end{tabular}

Note: Reaction temperature $: 250^{\circ} \mathrm{C}$, a DMF with $0.3 \% \mathrm{NaNO}_{3}$ was used as eluent at $30^{\circ} \mathrm{C}$. $\mathrm{M}_{\mathrm{w}}$ and $\mathrm{M}_{\mathrm{n}}$ was determined by GPC.[5]

\subsubsection{Effect of time on PDI}

PDI $\left(M_{w} / M_{n}\right)$ is the ratio of molecular weight of the polymer to the number of monomer units with variation in reaction time for the known amount of catalyst used at $250^{\circ} \mathrm{C}$. The effect of reaction time on the PDI indicates the rise and fall corresponding to the molecular weight as shown in (Fig. 3 ). It shows that the minimum value of PDI is at $4 \mathrm{hrs}$ of the synthesis time, corresponding to the minimum weight of the polymer at the same time. However, the Fig. 3 indicates that the maximum value of PDI lies with the range of the synthesis time of the polymer from 5 to 8 hrs, attributing to the fact that the value of PDI parameter corresponds to the molecular weight of the synthesized polymer.

\subsubsection{Effect of catalyst amount on molecular weight}

It is has been observed that at constant synthesis time the variation in catalyst amount does not show any corresponding behavior to the molecular weight of the polymer at constant synthesis time as shown in Fig. 4 . It has been observed that the maximum weight of the polymer is at $3 \%$ catalyst. After $3 \%$ catalyst, the weight of the polymer falls down as the catalyst amount is further increased, a situation which may be attributed to fact that in the reaction $\mathrm{AlCl}_{3}$ acts as initiator for thermal ring opening polymerization, but the excess amount of catalyst may stop the reaction due to the formation of stable acid base adduct with HCCP.

\subsubsection{Effect of catalyst amount on PDI}

The effect of the catalyst amount indicates that the $P D I$ increases as the catalyst amount increases from $3 \%$ to $8 \%$ for 5 hrs of the synthesis time at $250{ }^{\circ} \mathrm{C}$ as shown in Fig. 5. It is interesting to note that the behavior of PDI is almost same with the variation in the synthesis time as well as with the variation in the amount of the catalyst used for the synthesis of the polymer.

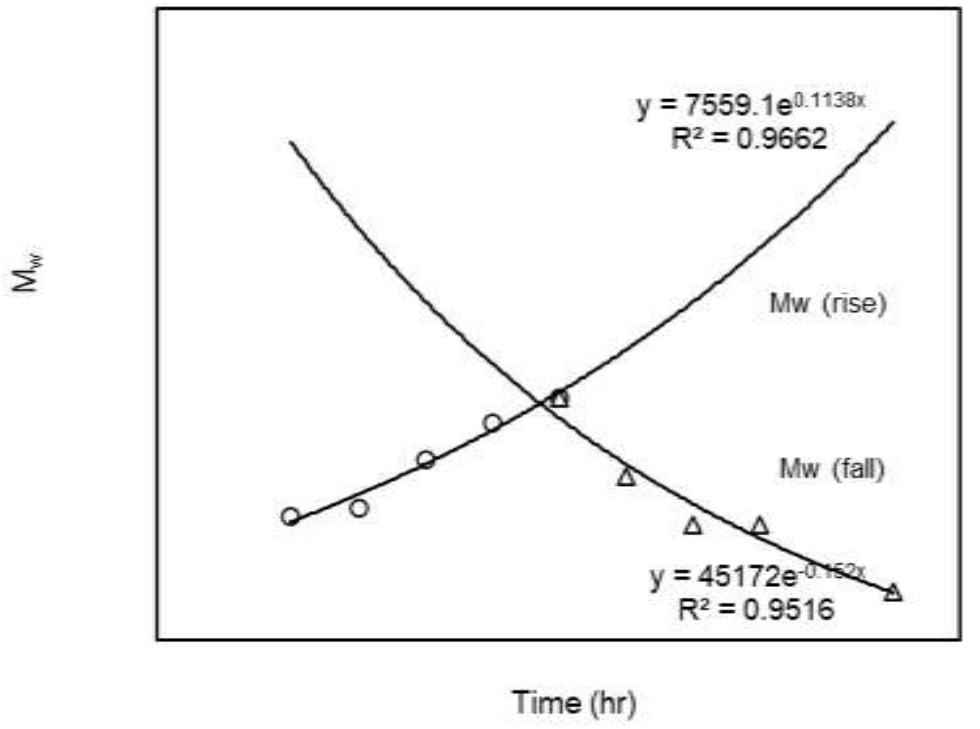

Figure 2: Effect of synthesis time on molecular weight using known amount of catalyst at $250{ }^{\circ} \mathrm{C}$.

\footnotetext{
$\mathrm{M}_{\mathrm{w}}=7559.1 \mathrm{e}^{0.1138 \mathrm{t}}$

$\mathrm{R}^{2}=0.9662$

$\mathrm{M}_{\mathrm{w}}=45172 \mathrm{e}^{-0.1523 \mathrm{t}}$

$\mathrm{R}^{2}=0.9516$
} 


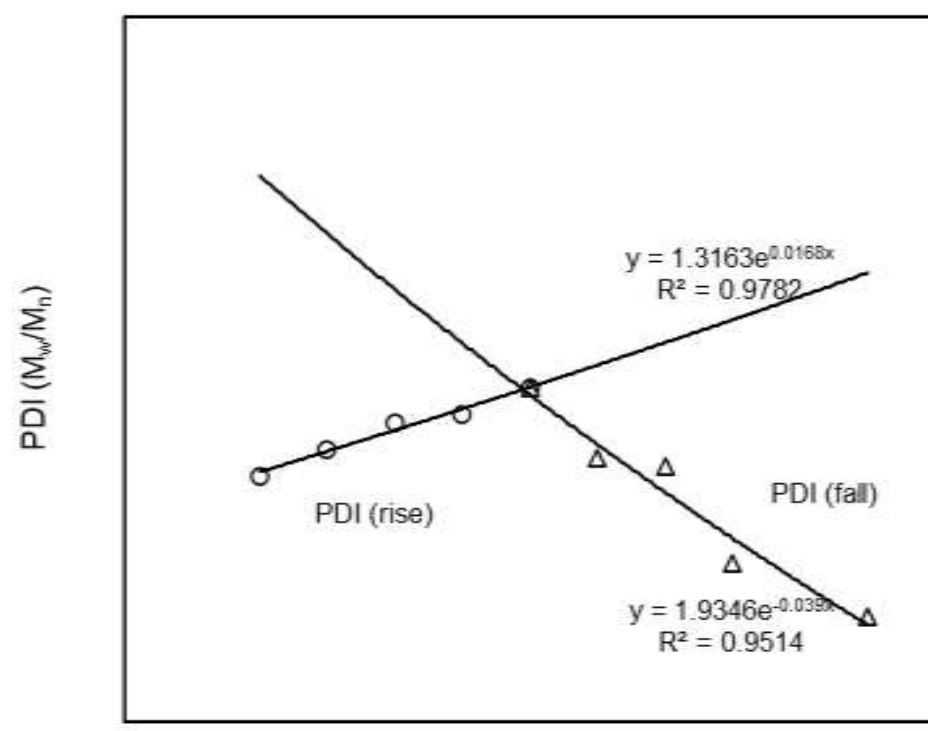

Time (hr)

Figure 3: Effect of synthesis time on PDI using known amount of catalyst at $250{ }^{\circ} \mathrm{C}$.

$P D=1.3062 \mathrm{e}^{0.0179 \mathrm{t}}$

$\mathrm{R}^{2}=0.9509$

$P D=1.935 \mathrm{e}^{-0.0391 \mathrm{t}}$

$\mathrm{R}^{2}=0.9583$

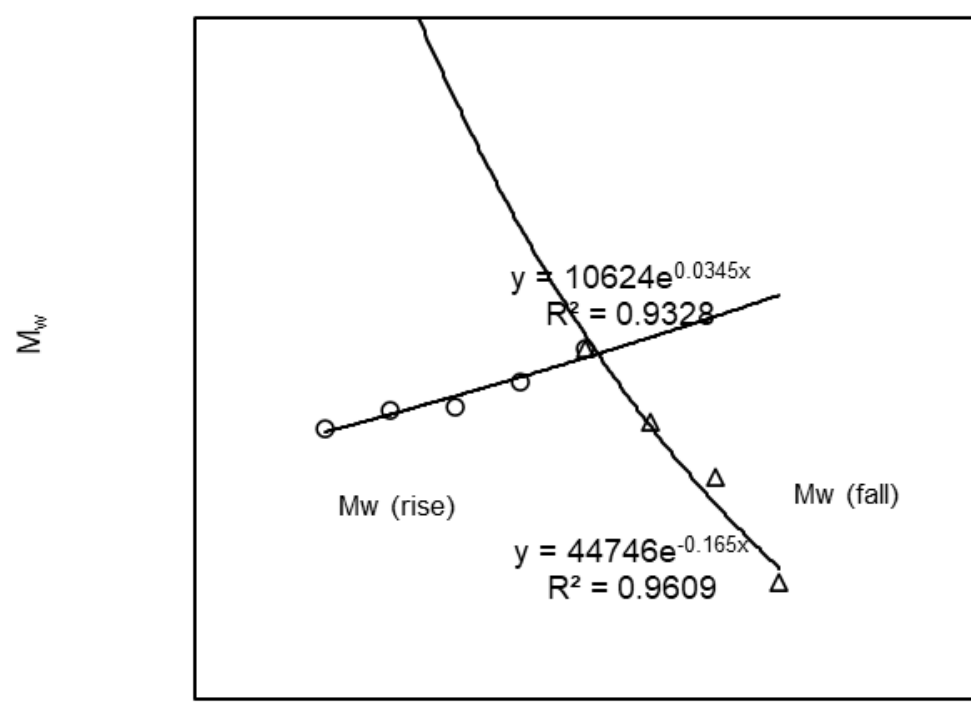

\section{Catalyst (\%)}

Figure 4: Effect of catalyst amount on molecular weight for known period of synthesis time at $250{ }^{\circ} \mathrm{C}$

$\mathrm{M}_{\mathrm{w}}=10624 \mathrm{e}^{0.0345 \mathrm{ct}}$

$\mathrm{R}^{2}=0.9328$

$\mathrm{M}_{\mathrm{w}}=44746 \mathrm{e}^{-0.1652 \mathrm{ct}}$

$\mathrm{R}^{2}=0.9609$ 


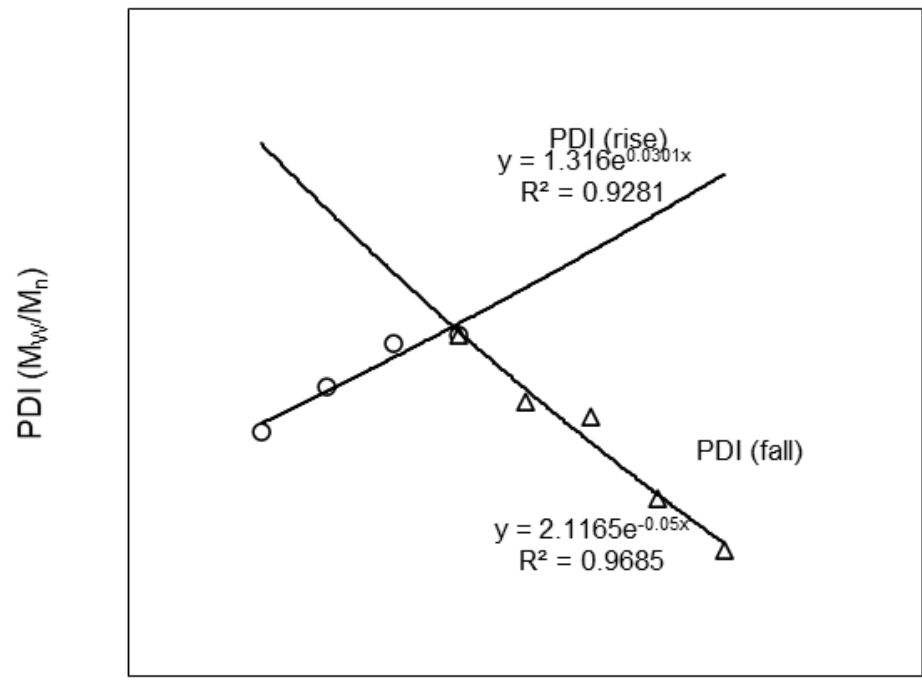

Catalyst (\%)

Figure 5: Effect of catalyst amount on PDI for known period of synthesis at $250^{\circ} \mathrm{C}$.

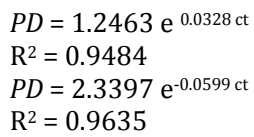

\subsection{Conclusion}

Analysis of the synthesis data indicates that the synthesis process of the polymer follows the exponential relation. The semi empirical model for the synthesis of the polymer can estimate the polymer weight at any time for the known amount of the catalyst used at $250{ }^{\circ} \mathrm{C}$. The value of coefficient of determination shows that the applicability of the models is promising.

\section{References}

[1] A.M. Amin, L. Wang, H. Yu, W. a. Amer, J. Gao, J. Huo, et al., "Synthesis and Characterization of Poly[bis(ethyl salicylate)phosphazenes] and Poly[bis(ethyl salicylate diethylamino)phosphazenes] and Their Hydrolytic Degradation”, J. Inorg. Organomet. Polym. Mater. 22, Pp. 196-204, 2011.

[2] A.M. Amin, L. Wang, J. Wang, H. Yu, J. Gao, C. Li, et al., "Recent Research Progress in the Synthesis of Polyphosphazene and Their Applications", Polym. Plast. Technol. Eng. Vol. 49, Pp. 1399-1405, 2010.

[3] A.M. Amin, L. Wang, J. Wang, H. Yu, J. Gao, C. Li, et al., "Recent Research Progress in the Synthesis of Polyphosphazene Elastomers and Their Applications", Polym. Plast. Technol. Eng. Vol. 49, Pp. 1399-1405, 2010.

[4] A.M. Amin, L. Wang, J. Wang, W. a. Amer, J. Huo, H. Yu, et al., "Synthesis and Characterization of Poly[bis(resorcinol monobenzoate) phosphazenes] and Poly[bis(resorcinol monobenzoate diethylamino) phosphazenes] and Their Self Assembly Behaviors", J. Inorg. Organomet. Polym. Mater. Vol. 21, Pp. 283-290, 2011.

[5] A.M. Amin, L. Wang, H. Yu, W. a. Amer, J. Gao, T. Yulei, et al., "Synthesis and Characterization of Poly[bis( p -oxybenzaldehyde diethylamino)phosphazenes], Poly[bis( p -oxybenzaldehyde)phosphazenes], Poly[bis(diethylamino)phosphazenes] and their Self- assembly Behaviors", J. Macromol. Sci. Part A. Vol. 48, Pp. 937-946, 2011.

[6] Polyphosphazenes for Biomedical Applications, John Wiley \& Sons, 2009.

[7] T. Potta, C. Chun, S.-C. Song, "Chemically crosslinkable thermosensitive polyphosphazene gels as injectable materials for biomedical applications", Biomaterials. Vol. 30, Pp. 6178-92, 2009.

[8] L.S. Nair, C.T. Laurencin, “Biodegradable polymers as biomaterials”, Prog. Polym. Sci. Vol. 32, Pp. 762-798, 2007.

[9] D.G. van der Poll, H.M. Kieler-Ferguson, W.C. Floyd, S.J. Guillaudeu, K. Jerger, F.C. Szoka, et al., "Design, synthesis, and biological evaluation of a robust, biodegradable dendrimer", Bioconjug. Chem. Vol. 21, Pp. 764-73, 2010.

[10] H.R. Allcock, N.L. Morozowich, "Bioerodible polyphosphazenes and their medical potential”, Polym. Chem. Vol. 3, 578-590, 2012.

[11] H.R. Allcock, T.J. Fuller, K. Matsumura, “Hydrolysis pathways for aminophosphazenes”, Inorg. Chem. Vol. 21, Pp. 515-521, 1982.

[12] Z.I. Zafar, M.A. Malana, H. Pervez, M.A. Shad, K. Momma, "Synthesis and Swelling Kinetics of a Cross-Linked pH-Sensitive Ternary Copolymer Gel System", Polym. Korea. Vol. 32, Pp. 219-229, 2008.

[13] C.-G. Li, Y.-Q. Yuan, Y.-F. Hu, J. Zhang, Y.-N. Tang, B.-Z. Ren, "Density functional theory study of the structures and electronic properties of copper and sulfur doped copper clusters", Comput. Theor. Chem. Vol. 1080, Pp. 47-55, 2016

[14] J. Castillo-tejas, O. Castrejón-gonzález, S. Carro, V. González-coronel, "Associative polymers. Part III : Shear rheology from molecular dynamics", Colloids Surfaces A Physicochem. Eng. Asp. Vol. 491, Pp. 37-49, 2016.

[15] J. Fried, A.A. Skelton, J.L. Kroger, J.R. Fried, A.A. Skelton, “Computational simulations of hydrolysis of phosphazene oligomer utilizing atom - centered 
density matrix propagation", Int. J. Quantum Chem. 2013.

[16] W.-L. Feng, S.X. Tian, "Ab initio molecular dynamics simulation study of dissociative electron attachment to $\mathrm{C} 6 \mathrm{H} 5(\mathrm{CH} 2) \mathrm{nCl}(\mathrm{n}=0,1,2,3,4)$ ", Int. J. Mass Spectrom. Pp. 8-11, 2016.

[17] R. Fondermann, M. Dolg, M. Raab, E. Niecke, "A quantum chemical ab initio study of the polymerization to polyhydridophosphazenes", Chem. Phys. Vol. 325, Pp. 291-298, 2006.

[18] J.L. Kroger, J.R. Fried, A.A. Skelton, “Computational simulations of hydrolysis of phosphazene oligomer utilizing atom-centered density matrix propagation”, Int. J. Quantum Chem. Vol. 113, Pp. 63-70, 2013.

[19] I. Teasdale, O. Brüggemann, "Polyphosphazenes: Multifunctional, biodegradable vehicles for drug and gene delivery", Polymers (Basel). Vol. 5, Pp. 161-187, 2013.

[20] B. Honarparvar, A.A. Skelton, "Molecular dynamics simulation and conformational analysis of some catalytically active peptides", J. Mol. Model. Vol. 21,2015 .

[21] A. V. Ratushny, S. A. Ramsey, and J. D. Aitchison. "Mathematical Modeling of Biomolecular Network Dynamics", Methods Mol Biol. Vol. 781, Pp. 415433, 2011.

[22] N. Chen, N. Lee, S. A. Bortolato \& D. M. Martino. "Experimental studies and mathematical modeling of the curing reaction of bioinspired copolymers", Green Chemistry Letters and Reviews, Vol. 11, No. 4, Pp. 387-398, 2018.

[23] T. A. Rozen'kova, L. I. Makeeva, I. N. Tsareva, L. V. Zhuravlev, A. V. Tokareva, M. V. Shablygin, "Mathematical modeling of synthesis processes for polymers which are prepared by the low-temperature polycondensation method", Fibre Chemistry, Vol. 17, Pp. 85-90, 1985.

[24] N. Chen, N. Lee, S. A. Bortolato and D. M. Martino. "Experimental studies and mathematical modeling of the curing reaction of bioinspired copolymers", Green Chemistry Letters and Reviews, Vol. 11, No. 4, Pp. 387-398, 2018.

[25] S. H. Jose R.Leiza José M.Asua. "A new approach for mathematical modeling of the dynamic development of particle morphology, Chemical Engineering Journal”, Vol. 304, Pp. 655-666, 2016.

[26] R.A.F., Machado, J.C., Pinto, P.H.H., Araújo, A, Bolzan. "Mathematical modeling of polystyrene particle size distribution produced by suspension polymerization”, Brazilian Journal of Chemical Engineering, Vol. 17, No. 4-7, Pp. 395-407, 2000.

[27] I. Grigoryev, S. Mustafina and S. Mustafina. "Mathematical Modeling of the Polymerization of Butadiene on Neodymium containing Catalyst system", ARPN Journal of Engineering and Applied Sciences. Vol. 14, No. 19, Pp. 3358-3363, 2019.

[28] Y. Chen, S. Zhou, Q. Li. "Mathematical modeling of degradation for bulk-erosive polymers: Applications in tissue engineering scaffolds and drug delivery systems", Acta Biomaterialia, Vol. 7, Pp. 1140-1149, 2011.

[29] W. J. Yoon, Y. S. Kim, I. S. Kim and K. Y. Choi. "Recent Advances in Polymer Reaction Engineering: Modeling and Control of Polymer Properties", Korean J. Chem. Eng., Vol. 21, No. 1, Pp. 147-167, 2004.

[30] J. A. Pojman, “Mathematical Modeling of Frontal Polymerization”, Math. Model. Nat. Phenom. Vol. 14, Pp. 604-614, 2019. 